\title{
BMJ Open The cross-sectional association of sitting time with carotid artery stiffness in young adults
}

\author{
Quan L Huynh, ${ }^{1}$ Christopher L Blizzard, ${ }^{1}$ James E Sharman, ${ }^{1}$ \\ Costan G Magnussen, ${ }^{1,2}$ Terence Dwyer, ${ }^{1,3}$ Alison J Venn ${ }^{1}$
}

To cite: Huynh QL, Blizzard CL, Sharman JE, et al. The cross-sectional association of sitting time with carotid artery stiffness in young adults. BMJ Open 2014;4:e004384.

doi:10.1136/bmjopen-2013004384

- Prepublication history for this paper is available online. To view these files please visit the journal online (http://dx.doi.org/10.1136/ bmjopen-2013-004384).

Received 1 November 2013 Revised 5 February 2014 Accepted 10 February 2014

\section{CrossMark}

\footnotetext{
${ }^{1}$ Menzies Research Institute Tasmania, University of Tasmania, Hobart, Australia ${ }^{2}$ Research Centre of Applied and Preventive Cardiovascular Medicine, University of Turku, Turku, Finland

${ }^{3}$ Murdoch Children's

Research Institute,

Melbourne, Australia

Correspondence to Dr Quan Long Huynh; Iqhuynh@utas.edu.au
}

\section{ABSTRACT}

Objectives: Physical activity is negatively associated with arterial stiffness. However, the relationship between sedentary behaviour and arterial stiffness is poorly understood. In this study, we aimed to investigate the association of sedentary behaviour with arterial stiffness among young adults.

Design: Cross-sectional.

Setting: 34 study clinics across Australia during 2004-2006.

Participants: 2328 participants ( $49.4 \%$ male) aged 26-36 years who were followed up from a nationally representative sample of Australian schoolchildren in 1985.

Measurements: Arterial stiffness was measured by carotid ultrasound. Sitting time per weekday and weekend day, and physical activity were self-reported by questionnaire. Cardiorespiratory fitness was estimated as physical work capacity at a heart rate of $170 \mathrm{bpm}$. Anthropometry, blood pressure, resting heart rate and blood biochemistry were measured. Potential confounders, including strength training, education, smoking, diet, alcohol consumption and parity, were self-reported. Rank correlation was used for analysis.

Results: Sitting time per weekend day, but not per weekday, was correlated with arterial stiffness (males $r=0.11 p<0.01$, females $r=0.08, p<0.05)$ and cardiorespiratory fitness (males $r=-0.14$, females $r=$ $-0.08, p<0.05$ ), and also with fatness and resting heart rate. One additional hour of sitting per weekend day was associated with $5.6 \%$ (males $p=0.046$ ) and $8.6 \%$ (females $\mathrm{p}=0.05$ ) higher risk of having metabolic syndrome. These associations were independent of physical activity and other potential confounders. The association of sitting time per weekend day with arterial stiffness was not mediated by resting heart rate, fatness or metabolic syndrome.

Conclusions: Our study demonstrates a positive association of sitting time with arterial stiffness. The greater role of sitting time per weekend day in prediction of arterial stiffness and cardiometabolic risk than that of sitting time per weekday may be due to better reflection of discretionary sitting behaviour.

\section{INTRODUCTION}

Physical activity is widely accepted as an important means to improve cardiovascular

\section{Strengths and limitations of this study}

- This is the first study to report a detrimental association of sitting time with arterial stiffness that was independent of physical activity and cardiorespiratory fitness.

- This is the first study to attribute a greater role to sitting time per weekend day than weekday in prediction of arterial stiffness and other cardiometabolic risk factors, which may be due to better discrimination of discretionary sitting behaviours of sitting time per weekend day than that of sitting time per weekday.

- Data were from a large nationally representative sample of Australians.

- Cross-sectional analysis, however, limits the causal inference that can be drawn about the relationship of sitting time with arterial stiffness.

health. Indeed, lack of physical activity is the second leading behavioural cause of death in the USA, following tobacco use. ${ }^{1}$ Many studies have reported participation in physical activity to be negatively associated with cardiometabolic risk factors including arterial stiffness. ${ }^{2}{ }^{3}$ Although the benefits of physical activity are well known, recent data show that levels of participation in moderate-tovigorous physical activity decline from childhood to adulthood and are low for adults. ${ }^{4}$

Sedentary behaviour, such as sitting, watching television and computer use, is ubiquitous in contemporary society and has become a new focus for research in health and physical activity. Sedentary behaviour is defined by the posture (sitting or reclining) and by the low levels of energy expenditure (typically in the range of 1-1.5 multiples of basal metabolic rate). ${ }^{5} 6$ Recent findings suggest that such activities should not be viewed as a replacement for moderate-tovigorous physical activity but as a distinct cardiovascular risk factor. ${ }^{7}$ Indeed, several studies have reported sedentary behaviour to independently predict greater cardiometabolic ${ }^{8-10}$ 
and mortality risk. ${ }^{11-15}$ That is, even for individuals who meet guideline recommendation on physical activity, being sedentary for prolonged periods may still compromise their health.

The relationship between sedentary behaviour and arterial stiffness, which is considered as one of the most important contributors to the increased cardiovascular risk associated with ageing, ${ }^{16}$ is however poorly understood. In this study of young adults, we examined the association of sedentary behaviour with arterial stiffness and with other cardiometabolic risk factors as a means to investigate the possible mechanisms. We hypothesised that sedentary behaviour is positively associated with arterial stiffness.

\section{METHODS}

\section{Study population}

This cross-sectional study used data from the Childhood Determinants of Adult Health (CDAH) study, which collected baseline data in 1985 on a nationally representative sample of 8498 Australian schoolchildren aged $7-15$ years. ${ }^{17}$ In this study, we included 2328 nonpregnant participants aged 26-36 years (49.4\% male) who attended 1 of 34 study clinics across Australia at follow-up during May 2004-May 2006. ${ }^{18}$ All participants provided written consent.

\section{Sedentariness, physical activity and physical fitness}

Participants reported how much time (hours and minutes) they spent sitting on a weekday (MondayFriday) and weekend day (Saturday and Sunday) during the past 7 days using the long version of the International Physical Activity Questionnaire (IPAQ). ${ }^{19}$ Time spent watching television, using computers and playing video games were also recorded in the same manner. Physical activity during the last 7 days was also reported using the long version of the IPAQ. ${ }^{19}$ Specifically, minutes/week spent on work-related, domestic and leisure physical activity at moderate and vigorous intensity were recorded together with time spent on active transport (classified as moderate intensity). These were summed to obtain total minutes of moderate-to-vigorous physical activity, and moderate and vigorous activities were weighted by their energy costby assigning metabolic equivalent of task (MET) values of 4 and 8, respectively-to obtain total energy expenditure. The associations of self-reported measures of sedentary behaviour and physical activity with a range of demographic and cardiometabolic factors in our study have been reported elsewhere. ${ }^{20}{ }^{21}$ Daily steps were recorded by Yamax Digiwalker SW-200 pedometers for 7 days as described previously. ${ }^{21}$ Cardiorespiratory fitness was estimated as physical work capacity at a heart rate of $170 \mathrm{bpm}\left(\mathrm{PWC}_{170}\right)$ by bicycle ergometry. ${ }^{22}$ Because the absolute workload achieved is partly a function of muscle mass, ${ }^{23} \mathrm{PWC}_{170}$ was adjusted for lean body mass $^{24}$ to create an index of cardiorespiratory fitness that is uncorrelated with lean body mass. ${ }^{25}$ For participants who were currently involved in strength training, total time spent on strength training was calculated from self-reported information on average duration of each workout, number of workouts per week, and the total years and months of training.

\section{Arterial stiffness and other cardiometabolic risk factors}

Arterial stiffness was measured in the left common carotid artery using a portable Acuson Cypress (Siemens Medical Solutions USA Inc, Mountainview, California, USA) platform with a $7 \mathrm{MHz}$ linear-array transducer by a single technician. ${ }^{26}$ Brachial systolic (SBP) and diastolic blood pressures (DBP) were measured during the ultrasound study with a mean of two readings used in this study. ${ }^{18}$ Three indices of carotid artery stiffness ${ }^{18} 25$ were calculated as follows:

$$
\begin{aligned}
& \mathrm{CD}=\left(\left[\mathrm{D}_{\mathrm{sbp}}-\mathrm{D}_{\mathrm{dbp}}\right] / \mathrm{D}_{\mathrm{dbp}}\right) /(\mathrm{SBP}-\mathrm{DBP}) \\
& \mathrm{SI}=\ln (\mathrm{SBP} / \mathrm{DBP}) /\left(\left[\mathrm{D}_{\mathrm{sbp}}-\mathrm{D}_{\mathrm{dbp}}\right] / \mathrm{D}_{\mathrm{dbp}}\right) \\
& \mathrm{YEM}=\left([\mathrm{SBP}-\mathrm{DBP}) \times \mathrm{D}_{\mathrm{dbp}}\right) /\left(\left[\mathrm{D}_{\mathrm{sbp}}-\mathrm{D}_{\mathrm{dbp}}\right] / \mathrm{IMT}\right)
\end{aligned}
$$

where $D_{\text {sbp }}$ and $D_{d b p}$ are the end-systolic and enddiastolic diameters, respectively, and intima-media thickness (IMT) is carotid IMT. Carotid distensibility (CD), the inverse of stiffness, measures the passive expansion and contraction of the arterial wall with changes in blood pressure. Stiffness index (SI) is a measure of stiffness that is relatively independent of pressure. Young's elastic modulus (YEM) is an estimate of stiffness per millimetre of IMT.

Resting heart rate (RHR) was measured while sitting after at least a 5 min rest. Weight, height and waist circumference were measured. ${ }^{18}$ Body mass index (BMI) was calculated as weight $(\mathrm{kg}) /$ height $(\mathrm{m})^{2}$. Sum of skinfolds at biceps, triceps, iliac crest and supraspinale was used. ${ }^{27}$ Glucose, high-density lipoprotein cholesterol (HDL-C), triglyceride and insulin concentrations were measured in $12 \mathrm{~h}$ overnight fasting blood samples. ${ }^{18}$ Low-density lipoprotein cholesterol (LDL-C) concentration was calculated using the Friedewald formula. ${ }^{28}$ Metabolic syndrome status was determined by using the 2009 harmonised definition proposed jointly by the International Diabetes Federation, National Heart, Lung and Blood Institute, American Heart Association, World Heart Federation, International Atherosclerosis Society, and the International Association for the Study of Obesity. ${ }^{29}$ A continuous metabolic syndrome score was calculated using the method described by Wijndaele et $a \vec{l}^{30}$ as reported previously. ${ }^{27}$ Briefly, the score was calculated by applying sex-specific principal component analysis to the normalised metabolic syndrome risk factors (including waist circumference, SBP, DBP, HDL-C, triglycerides and glucose). Two principal components that explained $34 \%$ and $26 \%$ of the variance in males and $31 \%$ and $25 \%$ of the variance in females were identified. These principal components were then 
summed, weighted according to the relative proportion of variance explained, to compute the continuous metabolic syndrome score.

\section{Covariates}

Data on smoking (never smoker, ex-smoker and current smoker), alcohol consumption (g/week), diet (whether dietary guidelines on various types of food were met), highest education and parity were obtained by questionnaire. $^{18} 31$

\section{Statistical analyses}

Right-skewed outcome data were appropriately transformed before estimation of means. The rank correlations were estimated by applying Pearson's correlation to the rank of variables. The associations of time spent watching television, and of time using a computer or playing video games, per weekday and weekend day with the outcomes were similar to, but somewhat weaker than, those of total sitting time per weekday and weekend day with the outcomes (not shown). For brevity, we reported the associations of total sitting time. Because only leisure-time vigorous physical activity but not less intensive forms of physical activity were associated with arterial stiffness among the young participants included in our study (not shown), the correlations presented in table 3 were adjusted for leisure-time vigorous physical activity. Adjustment for total physical activity provided similar results (not shown). There was no difference in self-reported moderate-to-vigorous physical activity in childhood between the participants at follow-up and the nonparticipants who dropped out from the baseline sample ( $p=0.62)$. However, the non-participants had lower socioeconomic status, lower levels of school academic performance, higher BMI, greater waist circumference and lower cardiorespiratory fitness in childhood in 1985 than the participants included in this study (all $\mathrm{p}<0.05)$. Using these characteristics, we calculated the probability of participation at follow-up for each participant at baseline. We then weighted the associations of sitting time with the outcomes among the participants using inverse probability weighting; this gave estimates of the association of interest with the inclusion of non-participants at follow-up represented by those similar to them at baseline in terms of socioeconomic status, school performance, BMI, waist and fitness. The weighted results were very similar to those presented in this manuscript (not shown), and thus give us confidence that the drop-outs did not influence our results. STATA V.12 (Statacorp, College Station, Texas, USA) was used for analyses.

\section{RESULTS}

Characteristics of participants are shown in table 1. Of the 2328 participants included in the analysis, 1246 (54\%) of them spent at least $5 \mathrm{~h}$ sitting/weekday, whereas $900(39 \%)$ of them spent at least $5 \mathrm{~h}$ sitting/ weekend day. On average, the male participants spent more time sitting and watching television or using computers or video games $($ all $\mathrm{p}<0.05)$, but had greater steps/day and greater self-reported moderate-to-vigorous physical activity, than their female counterparts $(\mathrm{p}<0.05)$. Computer use in this study included time using a computer at work and at home. 91\% (2122/ 2328) of our participants had a job or were students, and were likely to use a computer frequently. This may explain the large proportion of total sitting time in our study attributed to watching television, using computers and playing video games. The males had a lower mean value of $\mathrm{CD}$ and higher mean values of SI and YEM (ie, stiffer arteries) than the females (all $\mathrm{p}<0.001$ ). With the exception of RHR and skinfolds, all other cardiometabolic risk factors were greater among the males than the females (all $\mathrm{p}<0.001$ ).

Levels of education were positively correlated with sitting time per weekday, and with time using a computer per weekday and weekend day, but was negatively associated with time watching television per weekday and weekend day (all $\mathrm{p}<0.001$ for each sex). Among females, both sitting time per weekday and per weekend day were negatively correlated with parity $(p<0.001)$. Sitting time was strongly correlated with time spent watching television or using computers or video games per week (males $\mathrm{r}=0.50$, females $\mathrm{r}=0.56$ ), per weekday (males $\mathrm{r}=0.50$, females $\mathrm{r}=0.57$ ) and per weekend day (males $\mathrm{r}=0.49$, females $\mathrm{r}=0.39$ ), respectively (all $\mathrm{p}<0.001)$.

Table 2 shows rank correlations of sitting time with cardiorespiratory fitness, self-reported physical activity and average steps/day. While total MET.hour/week and average steps/day were negatively correlated with sitting time per weekday and per weekend day, cardiorespiratory fitness and self-reported time spent on vigorous physical activity were negatively correlated with sitting time per weekend day only. Among males and females who were currently doing strength training, sitting time per weekend day but not per weekday was negatively correlated with total training time $(p<0.05)$. Similar to sitting time, time spent watching television, using computers and playing video games per weekend day, but not per weekday, was inversely correlated with cardiorespiratory fitness (males $\mathrm{r}=-0.15$, females $\mathrm{r}=-0.15$ ) and self-reported leisure-time vigorous physical activity (males $\mathrm{r}=-0.08$, females $\mathrm{r}=-0.05$ ).

Table 3 shows rank correlations of sitting time with arterial stiffness, RHR, skinfolds and continuous metabolic syndrome scores. In general, sitting time per weekend day was more strongly correlated with arterial stiffness and other cardiometabolic risk factors than sitting time per weekday. These correlations, with an exception of the correlation between sitting time and continuous metabolic syndrome scores among females, were not substantially altered after adjusting for either self-reported physical activity or objectively-measured steps/day, and for other potential confounders 
Table 1 Characteristics of participants

\begin{tabular}{|c|c|c|c|c|}
\hline & \multicolumn{2}{|c|}{ Males $(n=1150)$} & \multicolumn{2}{|c|}{ Females $(n=1178)$} \\
\hline & Mean & (SD) & Mean & (SD) \\
\hline Age (year) & 31.6 & $(2.6)$ & 31.3 & $(2.6)$ \\
\hline \multicolumn{5}{|l|}{ Sitting time } \\
\hline Per week (h) & 39.9 & $(21.1)$ & 37.1 & $(18.7)$ \\
\hline Per weekday (h) & 6.1 & $(3.6)$ & 5.7 & (3.2) \\
\hline Per weekend day (h) & 4.9 & $(2.7)$ & 4.5 & $(2.6)$ \\
\hline \multicolumn{5}{|l|}{ Television, computer, video games } \\
\hline Per week (h) & 32.4 & $(22.1)$ & 27.1 & $(18.8)$ \\
\hline Per weekday (h) & 4.9 & (3.8) & 4.3 & (3.4) \\
\hline Per weekend day (h) & 4.0 & $(3.1)$ & 2.8 & (2.1) \\
\hline Average steps per day & 8819 & (3426) & 8575 & (2932) \\
\hline Total active $\mathrm{h} /$ week $^{*}$ & 11.3 & $(8.7)$ & 10.8 & $(7.9)$ \\
\hline Total MET h/week* & 52.6 & $(44.1)$ & 42.2 & (33.3) \\
\hline Vigorous leisure-time activity (h/week) & 1.5 & $(2.5)$ & 1.0 & $(1.9)$ \\
\hline Carotid distensibility $(\% / 10 \mathrm{~mm} \mathrm{Hg})$ & 1.94 & $(0.64)$ & 2.35 & $(0.79)$ \\
\hline Stiffness index & 5.29 & $(1.82)$ & 4.83 & (1.68) \\
\hline Young's elastic modulus ( $\mathrm{mm} \mathrm{Hg} \times \mathrm{mm}$ ) & 293.3 & (111.5) & 230.3 & (87.4) \\
\hline Resting heart rate (bpm) & 68.3 & $(9.9)$ & 73.2 & $(9.7)^{\prime}$ \\
\hline $\mathrm{PWC}_{170}(\mathrm{~W})$ & 193.7 & $(45.1)$ & 127.9 & (30.5) \\
\hline Total time of strength training $(\mathrm{h})$ & 205.0 & $(614.9)$ & 52.8 & $(153.4)$ \\
\hline Body mass index $\left(\mathrm{kg} / \mathrm{m}^{2}\right)$ & 25.9 & $(3.9)$ & 23.9 & $(4.2)$ \\
\hline Waist circumference (cm) & 88.0 & (9.8) & 75.7 & (9.6) \\
\hline Skinfolds (mm) & 61.7 & (25.9) & 73.4 & (30.8) \\
\hline Systolic pressure (mm Hg) & 124.6 & $(10.7)$ & 110.5 & (10.1) \\
\hline Diastolic pressure (mm Hg) & 74.5 & (8.9) & 69.8 & $(8.6)$ \\
\hline Insulin (mU/L) & 6.33 & (4.0) & 5.96 & (3.35) \\
\hline Glucose (mmol/L) & 5.14 & $(0.42)$ & 4.84 & $(0.40)$ \\
\hline HDL-cholesterol (mmol/L) & 1.26 & $(0.25)$ & 1.51 & $(0.33)$ \\
\hline LDL-cholesterol (mmol/L) & 3.04 & $(0.84)$ & 2.74 & $(0.74)$ \\
\hline Triglycerides $(\mathrm{mmol} / \mathrm{L})$ & 1.03 & (0.65) & 0.81 & $(0.42)$ \\
\hline Continuous metabolic syndrome score & 0.00 & $(0.71)$ & 0.00 & $(0.71)$ \\
\hline Metabolic syndrome $\ddagger$ & $11.8 \%$ & $(136)$ & $5.1 \%$ & $(60)$ \\
\hline \multicolumn{5}{|c|}{$\begin{array}{l}\text { *Including moderate-to-vigorous physical activity. } \\
\text { †Data are for those who were doing strength training only (males } n=256 \text {, females } n=245 \text { ). } \\
\text { †Data are percentage (number). } \\
\text { PWC }{ }_{170} \text {, physical work capacity at a heart rate of } 170 \mathrm{bpm} \text {. } \\
\text { MET, metabolic equivalent of task. }\end{array}$} \\
\hline
\end{tabular}

Table 2 Rank correlations of sitting time with measures of cardiorespiratory fitness and physical activity

\begin{tabular}{|c|c|c|c|c|}
\hline Sitting time & CRF & VLPA & $\begin{array}{l}\text { Total } \\
\text { PAt }\end{array}$ & $\begin{array}{l}\text { Average } \\
\text { steps/day }\end{array}$ \\
\hline \multicolumn{5}{|l|}{ Males } \\
\hline Per week & $-0.07^{*}$ & -0.01 & $-0.42^{\star \star \star}$ & $-0.37^{\star \star \star}$ \\
\hline Per weekday & -0.05 & 0.01 & $-0.43^{\star \star *}$ & $-0.38^{\star \star \star}$ \\
\hline Per weekend day & $-0.14^{* * *}$ & $-0.10^{\star \star}$ & $-0.19^{\star \star \star}$ & $-0.21^{\star \star \star}$ \\
\hline \multicolumn{5}{|c|}{ Females } \\
\hline Per week & 0.03 & 0.03 & $-0.29^{\star \star *}$ & $-0.20^{\star \star \star}$ \\
\hline Per weekday & 0.05 & 0.04 & $-0.31^{\star \star \star}$ & $-0.19^{\star \star \star}$ \\
\hline Per weekend day & $-0.08^{*}$ & $-0.07^{\star}$ & $-0.13^{\star \star \star}$ & $-0.18^{\star \star \star}$ \\
\hline \multicolumn{5}{|c|}{$\begin{array}{l}\text { Total PA (total MET hour/week). } \\
{ }^{*} p<0.05 ;{ }^{* \star} p<0.01 ;{ }^{* \star *} p<0.001 \text {. } \\
\text { †lncluding moderate-to-vigorous physical activity. } \\
\text { CRF, cardiorespiratory fitness; MET, metabolic equivalent of task; } \\
\text { VLPA, vigorous leisure-time physical activity, } h / \text { week. }\end{array}$} \\
\hline
\end{tabular}

$(\mathrm{p}<0.05)$. Further adjustment for cardiorespiratory fitness did not change our findings either (not shown). The change in the correlations between sitting time and continuous metabolic syndrome score among females was due to adjustment for parity that was negatively correlated with sitting time and positively correlated with metabolic syndrome scores. In these cross-sectional data, one additional sitting hour per weekend day was associated with a $5.6 \%$ (males $\mathrm{p}=0.046$ ) and $8.6 \%$ (females $\mathrm{p}=0.05$ ) higher risk of metabolic syndrome. Adjusting for RHR moderately reduced the correlation of sitting time with arterial stiffness among males $(\mathrm{p}<0.05)$, and adjusting for fatness (BMI or waist or skinfolds), and either the continuous metabolic syndrome score or individual components of metabolic syndrome, only slightly reduced the correlation of sitting time with arterial stiffness (not shown). 
Table 3 Rank correlations of sitting time with arterial stiffness and other cardiometabolic risk factors

\begin{tabular}{|c|c|c|c|c|c|c|}
\hline Sitting time & CD & SI & YEM & RHR & Skinfolds & cMetS \\
\hline \multicolumn{7}{|l|}{ Males } \\
\hline \multicolumn{7}{|l|}{ Unadjusted correlation } \\
\hline Per weekday & -0.05 & $0.08^{*}$ & 0.02 & $0.08^{\star \star}$ & 0.05 & -0.00 \\
\hline Per weekend day & $-0.12^{\star \star}$ & $0.12^{\star \star \star}$ & $0.09^{* *}$ & $0.13^{\star * *}$ & 0.06 & $0.08^{\star *}$ \\
\hline \multicolumn{7}{|l|}{ Adjusted correlation $†$} \\
\hline Per weekday & -0.05 & $0.08^{*}$ & 0.03 & $0.08^{\star \star}$ & 0.05 & 0.01 \\
\hline Per weekend day & $-0.11^{\star *}$ & $0.11^{\star *}$ & $0.10^{\star *}$ & $0.11^{\star \star *}$ & $0.06^{*}$ & $0.07^{*}$ \\
\hline \multicolumn{7}{|l|}{ Females } \\
\hline \multicolumn{7}{|l|}{ Unadjusted correlation } \\
\hline Per weekday & -0.01 & -0.01 & 0.01 & -0.03 & 0.04 & -0.00 \\
\hline Per weekend day & $-0.07^{*}$ & 0.06 & 0.05 & 0.00 & $0.10^{* *}$ & $0.08^{*}$ \\
\hline \multicolumn{7}{|l|}{ Adjusted correlation $†$} \\
\hline Per weekday & -0.01 & 0.00 & 0.03 & 0.01 & 0.06 & 0.04 \\
\hline Per weekend day & $-0.09^{*}$ & $0.08^{*}$ & $0.08^{*}$ & 0.02 & $0.11^{\star \star}$ & $0.12^{\star \star}$ \\
\hline
\end{tabular}

${ }^{\star * *} p<0.001 ;{ }^{* *} p<0.01 ;{ }^{*} p<0.5$.

†Adjusted for vigorous leisure-time physical activity, time spent on strength training, age, education, smoking, diet and alcohol, and for parity (females only).

$\mathrm{CD}$, carotid distensibility; cMetS (continuous metabolic syndrome score; RHR, resting heart rate; SI, stiffness index; YEM, Young's elastic modulus.

\section{DISCUSSION}

This study showed positive associations of sitting time per weekend day, but not per weekday, with arterial stiffness and other cardiometabolic risk factors. These associations were independent of self-reported and objectively measured physical activity, cardiorespiratory fitness and other potential confounders. The association of sitting time with arterial stiffness was not fully explained by RHR, fatness or metabolic syndrome, which are considered as potential mediators in this association.

Confidence in the reliability of our measures of sedentary behaviour in our study is strengthened by their plausible associations with sex, levels of education and self-reported and objectively measured physical activity. The greater role of sitting time per weekend day in prediction of arterial stiffness and cardiometabolic risks than that of sitting time per weekday may be due to the better discrimination of discretionary sitting behaviour. Sedentary behaviours are ubiquitous in contemporary society, and many occupations require a person to remain sedentary during weekdays. $^{32}$ An obvious example is office-based workers who have to spend many hours sitting during weekdays, and have more freedom to be physically active during non-working days that are usually weekends. This is consistent with our results because $54 \%$ of the participants in our study reported sitting at least $5 \mathrm{~h} /$ weekday, whereas $39 \%$ of them reported sitting at least $5 \mathrm{~h}$ /weekend day, and objectively-measured cardiorespiratory fitness was negatively associated with sitting time per weekend day but not with sitting time per weekday.

A recent review suggests that prolonged sitting may be an independent cardiovascular risk factor. ${ }^{7}$ In this study, we have shown a positive association of sitting time with arterial stiffness and, consistent with previous findings of adverse health effects of being sedentary that were independent of physical activity, ${ }^{7}$ adjusting for physical activity made little difference to the association of sitting time with arterial stiffness in our study. Because arterial stiffness independently predicts mortality, ${ }^{33}$ this relationship between sitting time and arterial stiffness may be a possible pathway through which sedentary behaviours are associated with mortality as reported in other studies. $^{11} 1214$ Although Moreau et $a \hat{l}^{34}$ have suggested that the greater carotid artery compliance in habitually exercising than sedentary postmenopausal females is mediated by an absence of oxidative stress, the mechanisms through which sedentary behaviour may influence arterial stiffness remain poorly understood. Unlike associations of physical activity or cardiorespiratory fitness with arterial stiffness, which we found to be mediated by RHR in our study, ${ }^{25}$ the association of sitting time with arterial stiffness was not mediated by RHR, fatness, metabolic syndrome or individual components of metabolic syndrome. Future studies are needed to explore the physiological mechanisms underlying the association of sitting time with arterial stiffness.

This study used a large national sample of young Australians on whom standardised measurements were made of an extensive range of study factors. To our knowledge, this is the first study that shows a positive association of sitting time with arterial stiffness in such a large population-based sample. The use of sitting time from self-report, rather than from objective measurements by accelerometers, is a limitation of our study. However, the self-reported sitting time in our study was well correlated with physical activity objectively measured by pedometers and cardiorespiratory fitness objectively measured by bicycle ergometry. The cross-sectional design of this study limits the causal inferences concerning the relationships of sitting time with arterial stiffness. 
We cannot rule out the possibility of a reverse causation whereby participants with greater arterial stiffness might be more sedentary in consequence. However, our findings on these young, generally healthy adults, who were unaware of their levels of arterial stiffness, link well with previous findings on the deleterious effects of sedentary behaviour on health, and may suggest a possible pathway through which too much sitting may lead to a higher risk of mortality.

In conclusion, our study shows positive associations of sitting time with arterial stiffness and other cardiometabolic risk factors, independent of physical activity, and attributes a greater predictive value of these health outcomes to sitting time per weekend day than sitting time per weekday among young adults. This may be due to the greater capability of sitting time during weekends in reflecting discretionary sitting behaviour of an individual, whereas sitting time during weekdays is probably determined more by occupational requirements. The association of sitting time with arterial stiffness was not fully explained by RHR, fatness or metabolic syndrome.

Acknowledgements The authors gratefully acknowledge the contributions of all CDAH staff and volunteers, and the participants.

Contributors QLH contributed to the design of the study, data analysis, drafting of the manuscript and coordination of the manuscript revision. CLB contributed to the design of the study, data analysis and critical revision of the manuscript. JES contributed to the design of the study and critical revision of the manuscript. CGM and TD contributed to data acquisition and critical revision of the manuscript. AJV contributed to the design of the study, data acquisition and critical revision of the manuscript.

Funding The CDAH study was funded by grants from the Australian National Health and Medical Research Council (grant number 211316), the Australian National Heart Foundation (award number GOOH 0578), the Tasmanian Community Fund (grant number D0013808) and Veolia Environmental Services. We gratefully thank the CDAH study sponsors (Sanitarium Health Food Company, ASICS Oceania and Target Australia).

Competing interests CLB, JES, CGM and AJV were supported by fellowships from the Australian National Health and Medical Research Council.

Ethics approval Southern Tasmania Health and Medical Research Ethics Committee.

Provenance and peer review Not commissioned; externally peer reviewed.

Data sharing statement No additional data are available.

Open Access This is an Open Access article distributed in accordance with the Creative Commons Attribution Non Commercial (CC BY-NC 3.0) license, which permits others to distribute, remix, adapt, build upon this work noncommercially, and license their derivative works on different terms, provided the original work is properly cited and the use is non-commercial. See: http:// creativecommons.org/licenses/by-nc/3.0/

\section{REFERENCES}

1. Mokdad AH, Marks JS, Stroup DF, et al. Actual causes of death in the United States, 2000. JAMA 2004;291:1238-45.

2. Tanaka H, Dinenno FA, Monahan KD, et al. Aging, habitual exercise, and dynamic arterial compliance. Circulation 2000; 102:1270-5.

3. Sugawara J, Otsuki T, Tanabe T, et al. Physical activity duration, intensity, and arterial stiffening in postmenopausal women. $A m ~ J$ Hypertens 2006;19:1032-6.

4. Troiano RP, Berrigan D, Dodd KW, et al. Physical activity in the United States measured by accelerometer. Med Sci Sports Exerc 2008:40:181-8
5. Ainsworth BE, Haskell WL, Whitt MC, et al. Compendium of physical activities: an update of activity codes and MET intensities. Med Sci Sports Exerc 2000;32(9 Suppl):S498-504.

6. Sedentary Behaviour Research. Letter to the editor: standardized use of the terms "sedentary" and "sedentary behaviours". Appl Physiol Nutr Metab 2012;37:540-2.

7. Dunstan DW, Thorp AA, Healy GN. Prolonged sitting: is it a distinct coronary heart disease risk factor? Curr Opin Cardiol 2011;26: 412-19.

8. Thorp AA, Healy GN, Owen N, et al. Deleterious associations of sitting time and television viewing time with cardiometabolic risk biomarkers: Australian Diabetes, Obesity and Lifestyle (AusDiab) study 2004-2005. Diabetes Care 2010;33:327-34.

9. Wijndaele K, Healy GN, Dunstan DW, et al. Increased cardiometabolic risk is associated with increased TV viewing time. Med Sci Sports Exerc 2010;42:1511-18.

10. Healy GN, Matthews CE, Dunstan DW, et al. Sedentary time and cardio-metabolic biomarkers in US adults: NHANES 2003-06. Eur Heart J 2011;32:590-7.

11. Dunstan DW, Barr EL, Healy GN, et al. Television viewing time and mortality: the Australian Diabetes, Obesity and Lifestyle Study (AusDiab). Circulation 2010;121:384-91.

12. Patel $A V$, Bernstein $L$, Deka $A$, et al. Leisure time spent sitting in relation to total mortality in a prospective cohort of US adults. Am J Epidemiol 2010;172:419-29.

13. Warren TY, Barry V, Hooker SP, et al. Sedentary behaviors increase risk of cardiovascular disease mortality in men. Med Sci Sports Exerc 2010;42:879-85.

14. Stamatakis E, Hamer M, Dunstan DW. Screen-based entertainment time, all-cause mortality, and cardiovascular events: populationbased study with ongoing mortality and hospital events follow-up. J Am Coll Cardiol 2011;57:292-9.

15. Wijndaele $\mathrm{K}$, Brage $\mathrm{S}$, Besson $\mathrm{H}$, et al. Television viewing time independently predicts all-cause and cardiovascular mortality: the EPIC Norfolk study. Int J Epidemiol 2011;40:150-9.

16. Lakatta EG, Levy D. Arterial and cardiac aging: major shareholders in cardiovascular disease enterprises: part I: aging arteries: a "set up" for vascular disease. Circulation 2003;107:139-46.

17. Dwyer T, Gibbons LE. The Australian Schools Health and Fitness Survey. Physical fitness related to blood pressure but not lipoproteins. Circulation 1994:89:1539-44.

18. Huynh Q, Blizzard L, Sharman J, et al. Relative contributions of adiposity in childhood and adulthood to vascular health of young adults. Atherosclerosis 2013;228:259-64.

19. Craig CL, Marshall AL, Sjostrom M, et al. International physical activity questionnaire: 12 -country reliability and validity. Med Sci Sports Exerc 2003;35:1381-95.

20. Schmidt MD, Cleland VJ, Thomson RJ, et al. A comparison of subjective and objective measures of physical activity and fitness in identifying associations with cardiometabolic risk factors. Ann Epidemiol 2008;18:378-86

21. Cleland VJ, Schmidt MD, Salmon J, et al. Correlates of pedometer-measured and self-reported physical activity among young Australian adults. J Sci Med Sport 2011;14:496-503.

22. Withers RT, Davies GJ, Crouch RG. A comparison of three W170 protocols. Eur J Appl Physiol Occup Physiol 1977;37:123-8.

23. Buskirk E, Taylor HL. Maximal oxygen intake and its relation to body composition, with special reference to chronic physical activity and obesity. J Appl Physiol 1957;11:72-8.

24. Dwyer T, Magnussen CG, Schmidt MD, et al. Decline in physical fitness from childhood to adulthood associated with increased obesity and insulin resistance in adults. Diabetes Care 2009;32:683-7.

25. Quan HL, Blizzard CL, Sharman JE, et al. Resting heart rate and the association of physical fitness with carotid artery stiffness. Am J Hypertens 2014;27:65-71.

26. Magnussen CG, Fryer J, Venn A, et al. Evaluating the use of a portable ultrasound machine to quantify intima-media thickness and flow-mediated dilation: agreement between measurements from two ultrasound machines. Ultrasound Med Biol 2006;32:1323-9.

27. Schmidt MD, Dwyer T, Magnussen CG, et al. Predictive associations between alternative measures of childhood adiposity and adult cardio-metabolic health. Int J Obes (Lond) 2011;35:38-45.

28. Friedewald WT, Levy RI, Fredrickson DS. Estimation of the concentration of low-density lipoprotein cholesterol in plasma, without use of the preparative ultracentrifuge. Clin Chem 1972;18:499-502.

29. Alberti KG, Eckel RH, Grundy SM, et al. Harmonizing the metabolic syndrome: a joint interim statement of the International Diabetes Federation Task Force on Epidemiology and Prevention; National Heart, Lung, and Blood Institute; American Heart Association; World 
Heart Federation; International Atherosclerosis Society; and International Association for the Study of Obesity. Circulation 2009;120:1640-5.

30. Wijndaele K, Beunen G, Duvigneaud N, et al. A continuous metabolic syndrome risk score: utility for epidemiological analyses. Diabetes Care 2006;29:2329.

31. Smith KJ, McNaughton SA, Gall SL, et al. Takeaway food consumption and its associations with diet quality and abdominal obesity: a cross-sectional study of young adults. Int J Behav Nutr Phys Act 2009;6:29.
32. Matthews CE, Chen KY, Freedson PS, et al. Amount of time spent in sedentary behaviors in the United States, 2003-2004. Am J Epidemiol 2008;167:875-81.

33. Laurent S, Cockcroft J, Van Bortel L, et al. Expert consensus document on arterial stiffness: methodological issues and clinical applications. Eur Heart J 2006;27:2588-605.

34. Moreau KL, Gavin KM, Plum AE, et al. Oxidative stress explains differences in large elastic artery compliance between sedentary and habitually exercising postmenopausal women. Menopause 2006;13:951-8. 